\title{
An assessment of the wind power dynamics in the European coastal environment
}

\author{
Eugen Rusu ${ }^{1,{ }^{*}}$, Alexandra Diaconita $^{1}$ and Alina Raileanu ${ }^{1,2}$ \\ ${ }^{1}$ Department of Mechanical Engineering, "Dunarea de Jos" University of Galati, Domneasca Street, 47, Galati 800008, Romania \\ ${ }^{2}$ Danubius International Business School, 3 Galati Street, Danubius University, 800654 Galati, Romania
}

\begin{abstract}
The objective of the proposed work is to assess the possible wind power dynamics along the European coastal environment in the context of the very predictable future development of the offshore wind energy extraction. From this perspective, 15 reference points have been selected in the Baltic, Mediterranean and Black seas, representing 5 representative locations for each sea, respectively. The proposed analysis is based on the wind fields provided by a Regional Climate Model (RCM) for the future time period 2021-2050. These data are processed and analysed considering the Representative Concentration Pathway (RCP) scenarios 4.5 and 8.5. In the first RCP scenario (4.5), an enhancement of the greenhouse gas emissions until 2040 is considered followed afterwards by a decline. On the other hand, the second scenario assumes that the greenhouse gas emissions enhancement will continue during the entire 21 st century and after. The first scenario is considered as the most realistic approach, while the second as the most pessimistic. Furthermore, in order to complete the picture an analysis of the historical wind data coming from the same RCM for the past 30-year period 1976-2005 is also carried out. In this way, a more comprehensive image of the wind power dynamics in the some relevant locations from the European coastal environment is provided. In order to enlarge the perspective, the analysis of the historical data is also extended for some locations in the North Sea, where wind farms already operate. The results indicate a slight enhancement of the average wind power in most of the locations considered. This enhancement appears to be stronger for RCP8.5 than for RCP4.5. On the other hand, the maximum wind power is expected to have much higher peaks for RCP8.5 and this especially concerns the western side of the Black Sea. The work is still on going and the analysis will be extended in both space and time covering more coastal locations and the time period until the end of the $21^{\text {st }}$ century.
\end{abstract}

\section{Introduction}

There is an obvious increasing worldwide energy request. On the other hand, the reduction of greenhouse gas emissions represents a priority that can no longer be postponed. Climate changes represent a reality and the sea environment appears to be very sensitive to these changes [1]. From this perspective, increasing the extraction of the renewable energy represents a high priority in the light of the necessity for a drastically decrease of the emissions of carbon dioxide. The European Union (EU) is now one of the most active players in the attempt to reduce the emissions and substantially increase the weight of the renewables in the total energy portfolio. Thus by 2030 it expected that more than $30 \%$ of the energy produced in the EU to be renewable.

While the land is almost saturated, in the sea environment there are large spaces and resources that can be considered for the implementation of the renewable projects $[2,3]$. Offshore wind represents one of the most dynamic and promising industries $[4,5]$. This is based on a proven technology which has been rapidly developed and adapted, the most promising directions being represented by enlarging the wind turbines and introducing the multirotor approach [6].

Besides the technical issues related to a successful operation in the harsh marine environment, another challenge consists in achieving reductions as regards the Levelized Cost of Energy (LCOE). According to many estimations a realistic LCOE target of 2019 for the offshore wind is about $7 \mathrm{c} € / \mathrm{kWh}$ and it will continue to decrease in the next years $[7,8]$. This means that the offshore wind is already commercially efficient. Furthermore, at this moment it is not only the cheapest marine renewable energy resource but it becomes now cheaper also than some conventional onshore resources. For example, the LCOE for the atomic energy is still about 11-12 $\mathrm{c} € / \mathrm{kWh}$, which is already much more than the offshore wind in the conditions when the atomic energy may present also higher risks. The wind is considerably stronger and steadier offshore and besides the fix turbines, the floating platforms represent and emerging technology that will allow wind energy extraction as well as hybrid approaches covering large spaces in the sea.

\footnotetext{
Corresponding author: eugen.rusu@ugal.ro
} 
In this context, the present work synthetises the results of some previous studies presenting the wind power potential and its expected future dynamics in the most relevant European seas. This includes the Baltic Sea, the Mediterranean Sea, the Black Sea, past and future projections. The proposed analysis is based on the wind fields provided by a Regional Climate Model for the future time period 2021-2050. These data are processed and analysed considering the Representative Concentration Pathway (RCP) scenarios 4.5 and 8.5. The historical data relates the 30-year period 1976-2005. In addition, some historical data in the North Sea corresponding to some locations where wind projects are already operational are also analysed for the 20-year period 1999-2018.

\section{Methods and materials}

20 reference points have been considered in the present work. Their positions and coordinates are indicated in Figure 1. The reference points P1-P5 are related to the coastal environment of the Baltic Sea. Furthermore, they correspond to locations where offshore wind farms already operate. Thus, P1 stands for Anholt wind farm with a capacity of $400 \mathrm{MW}, \mathrm{P} 2$ indicates the wind farm EnBW Baltic 2 with a capacity of $288 \mathrm{MW}, \mathrm{P} 3$ the wind farm Rød-sand II with 207MW, P4 Rød-sand I with $166 \mathrm{MW}$ and finally P5 indicates the wind farm EnBW Baltic 1 with a capacity of $48.3 \mathrm{MW}$. The next series of reference points P6-P10 are related to the European coastal environment of the Mediterranean Sea. Another group of reference points P11-P15 is focused on the Black Sea. Since most of the existent studies $[9,10]$ indicate the north western side of the sea as being more energetic all these points are considered in the north western side. For all these 15 reference points analyses of the wind conditions are provided in parallel for the 30year future period 2021-2050 against the historical data corresponding to the 30-year period 1976-2005. In addition an analysis corresponding to 5 locations from the North Sea is also made (reference points P16-P20). Unlike the core analysis, which is based on the data coming from the Climatic Wind Models, this last analysis covers only a 20-year period (1999-2018) and is based on reanalysis wind fields from the European Centre for Medium-range Weather Forecasts (ECMWF) [11]. The points considered correspond also to currently operating wind farms, as follows: P16 - Gemini Buiten Gaats \& ZeeEnergie with a capacity of $600 \mathrm{MW}, \mathrm{P} 17$ - Trianel Windpark Borkum with 200MW, P18 - Thanet with a capacity of $300 \mathrm{MW}, \mathrm{P} 19$ - Gode Wind with a total capacity of 504MW, and finally P20 corresponds to the wind farm Eneco Luchterduinen with 129MW.

For the analysis related to the reference point P1-P15, the wind data with a spatial resolution of 0.11 degrees and a time resolution of 6 hours, provided by the RCM (regional climate model), version RCA4 has been considered. The regional climate model that is operated at the Swedish Meteorological and Hydrologic Institute (SMHI) [12, 13], forced with boundary conditions from the global climate model (EC-EARTH) and available via the EURO-CORDEX database is used in the present work [14]. Three different analyses have been performed.

The first is related to the 30-year period 1976-2005 and considers the historical data. The second and the third relate both the 30-year period 2021-2050, but considering different RCP scenarios, RCP4.5 and RCP8.5, respectively. Such scenarios concerning the greenhouse gas emission correspond to a stabilization of radiative forcing after the $21 \mathrm{st}$ century at $4.5 \mathrm{~W} / \mathrm{m}^{2}$ for RCP4.5 and $8.5 \mathrm{~W} / \mathrm{m}^{2}$ for the case of RCP8.5. At this point it has to be highlighted that radiative forcing indicates the difference between the sunlight insolation absorbed by the Earth and the energy radiated back to space. Thus, a positive radiative forcing implies that Earth receives more energy from the Sun than it radiates to space, which causes warming. From this perspective, four different pathways are currently considered for the climate modelling, as they have been defined by the Intergovernmental Panel for Climate Change (IPCC). They describe different climate projections depending on the quantity of the emitted greenhouse gases in the future.

Thus, four RCPs are defined considering the possible range of radiative forcing values in the year 2100 relative to pre-industrial values. These are RCP2.6, RCP4.5, RCP6, and RCP8.5, corresponding to $+2.6,+4.5,+6.0$, and $+8.5 \mathrm{~W} / \mathrm{m}^{2}$, respectively. RCP 2.6 assumes that global annual peak between 2010-2020, declining substantially thereafter. Emissions in RCP 4.5 peak around 2040, and then decline. In RCP 6, emissions peak around 2080, then decline, while in RCP 8.5, emissions continue to rise throughout the 21 st century.

The numerical models provide the wind speed values at the height of 10 meters above the sea level. Since most of the wind turbines operate at higher heights above the sea level, the present work considers the results at the height of $80 \mathrm{~m}$. From this perspective, in order to translate the value of the wind speed from 10 to 80 meters a logarithmic law is considered [15]:

$$
U_{z}=U_{\text {zref }} \frac{\ln \left(z / z_{0}\right)}{\ln \left(z_{\text {ref }} / z_{0}\right)}
$$

Where: $U_{z}$ represents the wind speed at a height $\mathrm{z}$ (in this case $\mathrm{z}$ was considered to be $80 \mathrm{~m}$ ), $U_{\text {zref }}$ is the known wind spped at the height $z_{\text {ref }}$ (in this case $10 \mathrm{~m}$ ), $z_{0}$ represents the roughness length which was considered to be $0.0002 \mathrm{~m}$. The wind power density has the following formula $\left(P_{\text {wind }}-W / m^{2}\right)$ [7]:

$$
P_{\text {wind }}=\frac{1}{2} \rho_{\text {air }} U_{z}^{3}
$$

Where: $U_{z}$ represents the wind speed at a height $\mathrm{z}$ (in this case $\mathrm{z}$ was considered to be $80 \mathrm{~m}$ ), $\rho_{\text {air }}$ is the air density (having the value $1.225 \mathrm{~kg} / \mathrm{m}^{3}$ ). 


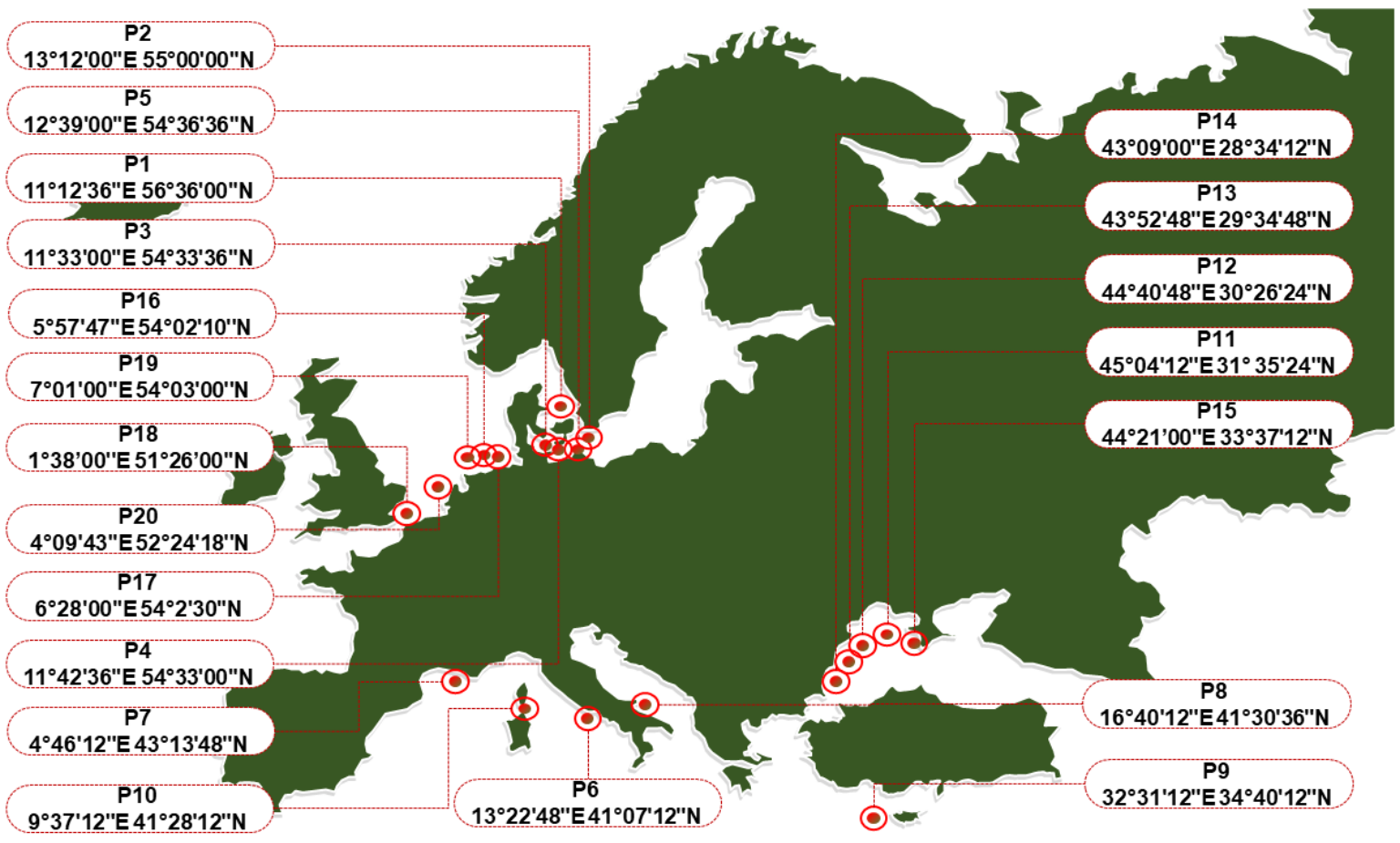

Figure 1. Map of Europe and the locations of the 20 reference points considered in this work

\section{Results and discussion}

Figure 2 presents the mean (Figure 2a) and maximum (Figure 2b) values of the wind power for the reference points $\mathrm{P} 1$ to $\mathrm{P} 15$ presenting in parallel the results for the two 30-year periods considered, 1976-2005 representing historical data and 2021-2050 considering the RCP4.5 scenario. The results presented in this figure show that while in terms of average wind power values for the future period only small enhancements are expected, as regards the maximum wind power values higher variations are predicted especially in the Baltic Sea (reference point P5) and in the Mediterranean Sea (Reference point P6).

Figure 3 presents the seasonal variations of the mean wind power, for the historical data (Figure 3a) and the future wind conditions according to RCP4.5 scenario. The results presented in this figure show that that there are not expected in the near future in average values higher seasonal variability of the wind power than the variability corresponding to the historical data. It has to be highlighted that in this study the winter time was considered the 6-month period between October to March while the summer time is the rest.

The wind statistics is presented in Tables 1, 2, 3 and 4. The data presented in these tables are mean and maximum values of the wind power, standard deviation, $95^{\text {th }}$ percentile and skewenes, computed according to their standard definitions.
Thus, Table 1 presents the wind power statistics at 80 $\mathrm{m}$ above the sea level for reference points P1-P15, which correspond to the seas Baltic, Mediterranean and Black. The results presented are computed for the 30 -year period 1976-2005. On the other hand, Table 2 presents the similar results concerning the wind power statistics at 80 $\mathrm{m}$ above the sea level for the same 15 reference points (P1-P15). The results presented are computed this time for the 30-year period 2021-2050 considering the RCP scenario 4.5 . Further on, Table 3 presents the wind power statistics at $80 \mathrm{~m}$ for reference points (P1-P5, P11-P15, corresponding to the Baltic and Black seas, respectively). These results correspond to the period 2021-2050 under RCP8.5 scenario. As it can be seen from these tables, in terms of average wind power values there are expected only small enhancements but there are not expected very high variations in the near future in relationship with the recent pasts for the coastal environments targeted. At the same time, in terms of maximum wind power values substantial enhancements are expected. These enhancements are more visible in the Baltic Sea as well as in some locations from the Mediterranean Sea (especially in the coastal environment south of France). More results concerning the wind power potential in the Baltic Sea are presented in [16]. As regards the Mediterranean Sea a more complete perspective of the wind power and its dynamics is presented in [17, 18]]. On the other hand, when considering the RCP8.5 scenario the highest enhancements of the maximum wind power are expected in the western side of the Black Sea [19]. 


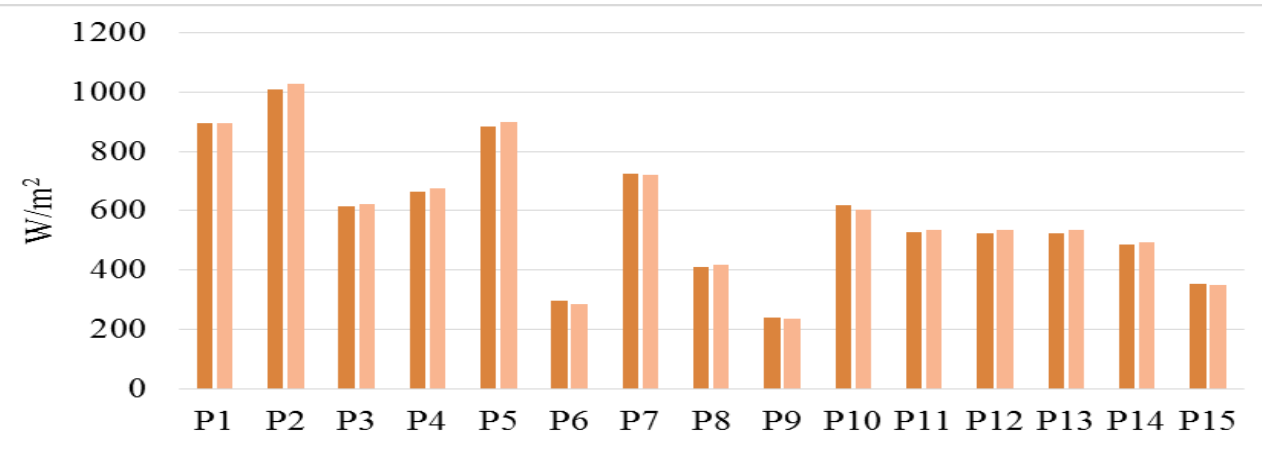

a)

$\square$ Historical data $\square \mathrm{RCP} 4.5$ scenario

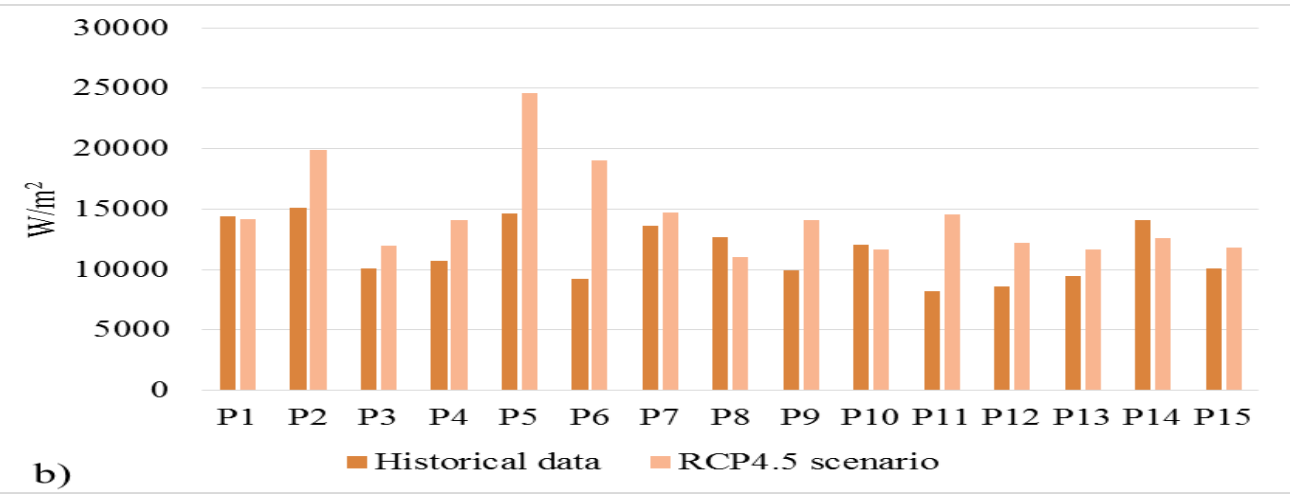

Figure 2. Mean (a) and maximum (b) values of the wind power for the reference points P1 to P15

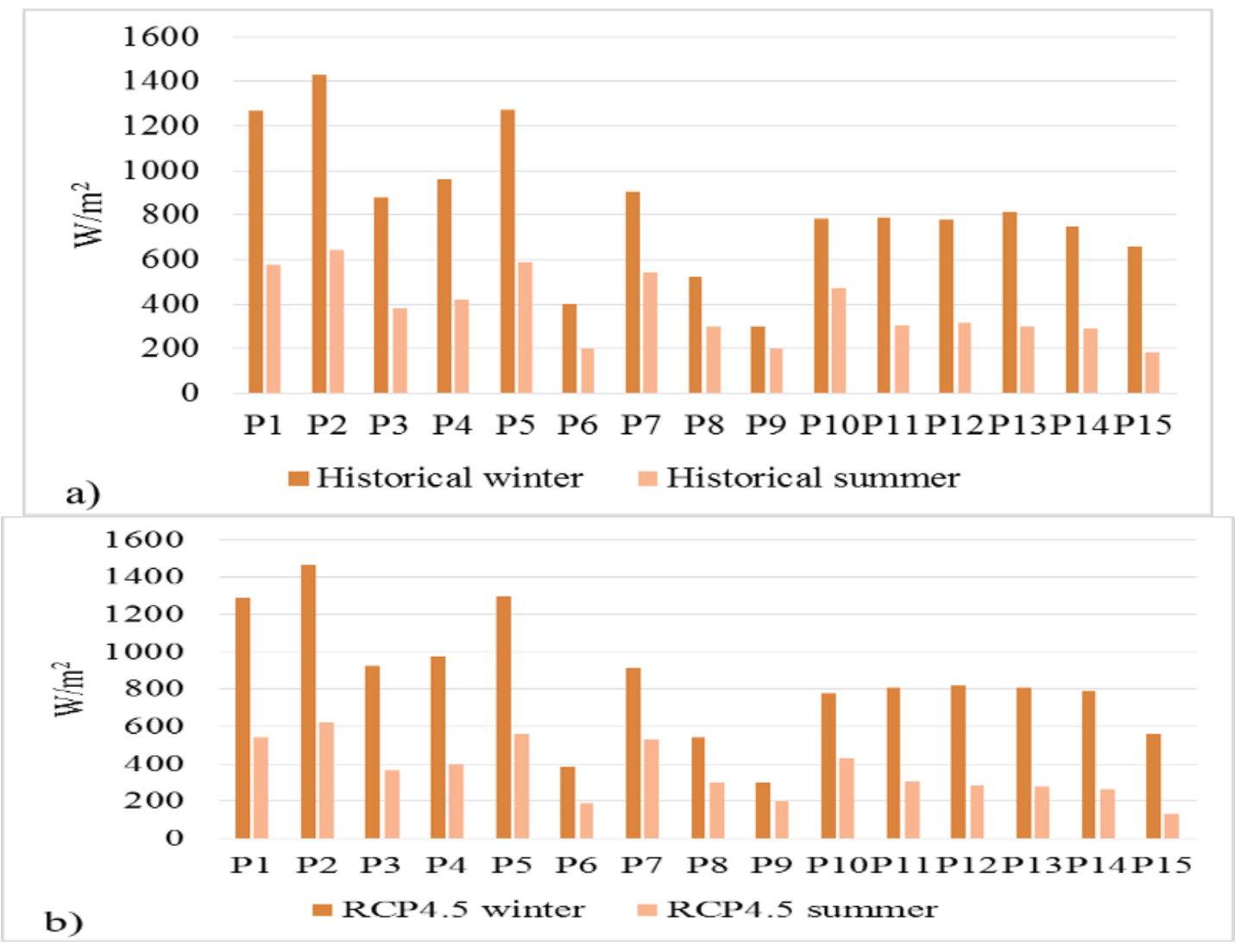

Figure 3. Seasonal variability of the mean wind power at the hub height of $80 \mathrm{~m}$, for historical a) and future wind data b). 
Table 1. Wind power statistics at $80 \mathrm{~m}$ for the reference points (P1-P15). Results computed for the 30-year period 1976-2005.

\begin{tabular}{|c|c|c|c|c|c|c|c|}
\hline Time period & Sea & $\begin{array}{c}\text { Reference } \\
\text { point }\end{array}$ & $\begin{array}{c}\text { Mean } \\
\left(\mathrm{W} / \mathbf{m}^{2}\right)\end{array}$ & $\begin{array}{c}\text { Max } \\
\left(\mathbf{W} / \mathbf{m}^{2}\right)\end{array}$ & $\begin{array}{c}\text { Std } \\
\left(\mathbf{W} / \mathbf{m}^{2}\right)\end{array}$ & $\begin{array}{c}\text { 95th } \\
\left(\mathrm{W} / \mathrm{m}^{2}\right)\end{array}$ & Skew \\
\hline \multirow{15}{*}{$\begin{array}{l}\text { Historical } \\
(1976-2005)\end{array}$} & \multirow{5}{*}{ Baltic } & P1 & 895 & 14365 & 983 & 2848 & 2.45 \\
\hline & & $\mathrm{P} 2$ & 1008 & 15077 & 1145 & 3297 & 2.45 \\
\hline & & P3 & 613 & 10086 & 746 & 2081 & 2.76 \\
\hline & & $\mathrm{P} 4$ & 665 & 10693 & 805 & 2249 & 2.72 \\
\hline & & P5 & 882 & 14673 & 1051 & 2953 & 2.67 \\
\hline & \multirow{5}{*}{ Mediterranean } & P6 & 298 & 9218 & 516 & 1278 & 4.05 \\
\hline & & P7 & 724 & 13607 & 975 & 2662 & 2.75 \\
\hline & & P8 & 410 & 12677 & 627 & 1586 & 3.76 \\
\hline & & P9 & 241 & 9959 & 400 & 887 & 5.41 \\
\hline & & P10 & 620 & 12012 & 829 & 2259 & 2.65 \\
\hline & \multirow{5}{*}{ Black } & P11 & 526 & 8166 & 684 & 1889 & 2.7 \\
\hline & & P12 & 524 & 8605 & 693 & 1893 & 2.8 \\
\hline & & P13 & 523 & 9447 & 706 & 1912 & 3 \\
\hline & & P14 & 487 & 14080 & 689 & 1820 & 3.4 \\
\hline & & P15 & 354 & 10114 & 517 & 1366 & 3.3 \\
\hline
\end{tabular}

Table 2. Wind power statistics at $80 \mathrm{~m}$ for the reference points (P1-P15). Results for the period 2021-2050 under RCP4.5 scenario.

\begin{tabular}{|c|c|c|c|c|c|c|c|}
\hline Time period & Sea & $\begin{array}{c}\text { Reference } \\
\text { point }\end{array}$ & $\begin{array}{c}\text { Mean } \\
\left(W / m^{2}\right)\end{array}$ & $\begin{array}{c}\text { Max } \\
\left(\mathbf{W} / \mathbf{m}^{2}\right)\end{array}$ & $\begin{array}{c}\text { Std } \\
\left(\mathbf{W} / \mathbf{m}^{2}\right)\end{array}$ & $\begin{array}{c}\text { 95th } \\
\left(\mathrm{W} / \mathrm{m}^{2}\right)\end{array}$ & Skew \\
\hline \multirow{15}{*}{$\begin{array}{c}\text { RCP4.5 } \\
(2021-2050)\end{array}$} & \multirow{5}{*}{ Baltic } & $\mathrm{P} 1$ & 894 & 14169 & 994 & 2854 & 2.5 \\
\hline & & $\mathrm{P} 2$ & 1027 & 19866 & 1189 & 3371 & 3.54 \\
\hline & & P3 & 621 & 11996 & 767 & 2131 & 2.88 \\
\hline & & $\mathrm{P} 4$ & 675 & 14050 & 831 & 2312 & 2.86 \\
\hline & & P5 & 900 & 24612 & 1099 & 3060 & 3.05 \\
\hline & \multirow{5}{*}{ Mediterranean } & $\mathrm{P} 6$ & 286 & 19053 & 517 & 1212 & 5.25 \\
\hline & & P7 & 720 & 14691 & 1007 & 2674 & 2.87 \\
\hline & & P8 & 419 & 11036 & 625 & 1599 & 3.61 \\
\hline & & P9 & 237 & 14062 & 391 & 889 & 6.52 \\
\hline & & $\mathrm{P} 10$ & 604 & 11665 & 832 & 2238 & 2.79 \\
\hline & \multirow{5}{*}{ Black } & P11 & 535 & 14563 & 717 & 1898 & 3.4 \\
\hline & & P12 & 534 & 12220 & 721 & 1940 & 3.2 \\
\hline & & P13 & 535 & 11618 & 734 & 1964 & 3.2 \\
\hline & & P14 & 495 & 12611 & 716 & 1866 & 3.5 \\
\hline & & $\mathrm{P} 15$ & 350 & 11822 & 535 & 1366 & 3.9 \\
\hline
\end{tabular}

Table 3. Wind power statistics at $80 \mathrm{~m}$ for the reference points (P1-P5, P11-P15). Results for period 2021-2050, RCP8.5 scenario.

\begin{tabular}{|c|c|c|c|c|c|c|c|}
\hline Time period & Sea & $\begin{array}{c}\text { Reference } \\
\text { point }\end{array}$ & $\begin{array}{c}\text { Mean } \\
\left(\mathrm{W} / \mathbf{m}^{2}\right)\end{array}$ & $\underset{\left(\mathbf{W} / \mathbf{m}^{2}\right)}{\operatorname{Max}}$ & $\begin{array}{c}\text { Std } \\
\left(\mathbf{W} / \mathbf{m}^{2}\right)\end{array}$ & $\begin{array}{c}\text { 95th } \\
\left(\mathrm{W} / \mathbf{m}^{2}\right)\end{array}$ & Skew \\
\hline \multirow{10}{*}{$\begin{array}{c}\text { RCP8.5 } \\
(2021-2050)\end{array}$} & \multirow{5}{*}{ Baltic } & P1 & 895 & 14528 & 984 & 2811 & 2.50 \\
\hline & & P2 & 1015 & 13044 & 1166 & 3331 & 2.53 \\
\hline & & P3 & 610 & 11587 & 754 & 2076 & 2.94 \\
\hline & & $\mathrm{P} 4$ & 663 & 12188 & 814 & 2254 & 2.87 \\
\hline & & P5 & 890 & 14874 & 1074 & 2991 & 2.79 \\
\hline & \multirow{5}{*}{ Black } & P11 & 537 & 15132 & 735 & 1936 & 3.3 \\
\hline & & P12 & 536 & 10575 & 748 & 1945 & 3.3 \\
\hline & & P13 & 538 & 34168 & 802 & 1959 & 6.2 \\
\hline & & P14 & 493 & 12028 & 737 & 1820 & 4.0 \\
\hline & & P15 & 366 & 10693 & 546 & 1434 & 3.43 \\
\hline
\end{tabular}

Table 4. Wind power statistics at $80 \mathrm{~m}$ for the reference points (P16-P20). Results for ther period 1999-2018.

\begin{tabular}{ccccccc}
\hline Sea/period & $\begin{array}{c}\text { Reference } \\
\text { point }\end{array}$ & $\begin{array}{c}\text { Mean } \\
\left(\mathbf{W} / \mathbf{m}^{2}\right)\end{array}$ & $\begin{array}{c}\mathbf{M a x} \\
\left(\mathbf{W} / \mathbf{m}^{2}\right)\end{array}$ & $\begin{array}{c}\text { Std } \\
\left(\mathbf{W} / \mathbf{m}^{\mathbf{2}}\right)\end{array}$ & $\begin{array}{c}\mathbf{9 5 t h} \\
\left(\mathbf{W} / \mathbf{m}^{2}\right)\end{array}$ & Skew \\
\hline \multirow{3}{*}{ North Sea } & $\mathrm{P} 16$ & 814 & 14884 & 1058 & 2.939 & 2920 \\
\cline { 2 - 7 }$(1999-2018)$ & $\mathrm{P} 17$ & 822 & 14226 & 1064 & 2.923 & 2928 \\
\cline { 2 - 7 } & $\mathrm{P} 18$ & 593 & 14342 & 810 & 3.010 & 2192 \\
\cline { 2 - 7 } & $\mathrm{P} 19$ & 777 & 14423 & 1011 & 2.973 & 2771 \\
\cline { 2 - 7 } & $\mathrm{P} 20$ & 562 & 13318 & 786 & 3.176 & 2117 \\
\hline
\end{tabular}


Finally, in order to provide a more complete picture of the wind power resources along the European coasts, Table 3 presents the wind power statistics at $80 \mathrm{~m}$ for reference points (P16-P20), located in the North Sea and targeting sites where wind farms already operate since several years. The results presented are processed for the period 1999-2018. Further details concerning the wind conditions in the North Sea, as well as the performances of some state of the art wind turbines are detailed in [20].

\section{Conclusions}

In the present work an analysis of the wind power along the European sea coasts is presented. This analysis comprises the coastal environments of the Baltic Sea, the Mediterranean Sea, the Black Sea and the North Sea. For the first three case studies, there are presented in parallel results for two time intervals each of 30 years. The first interval concerns historical data for the period 1976-2005 while the second analysis some projections of the wind fields for the interval 2021-2050 modelled considering the RCP scenarios 4.5 and 8.5. In addition, in order to provide a better picture of the wind conditions along the European sea coasts of Europe an analysis of the wind power in the North Sea is also provided covering this time the 20-year period 19992018.

As regards the historical data, the results show that the northern part of Europe has higher wind energy resources with average wind powers that often exceed $800 \mathrm{~W} / \mathrm{m}^{2}$, being also noticed in some places average wind power values of about $1000 \mathrm{~W} / \mathrm{m}^{2}$ as in the case of the reference point $\mathrm{P} 2$, which corresponds to the location of the wind farm EnBW Baltic 2. On the other hand, also in the Mediterranean and the Black seas there can be noticed relatively significant wind power resources reflected by average values of the wind power greater than $500 \mathrm{~W} / \mathrm{m}^{2}$ (as for example for the reference points P6 corresponding to the south of France or P11 in the north western side of the Black Sea).

In relationship with the future expectations for the wind power dynamics corresponding to the period 2021-2050, it can be noticed that we may expect a slight general enhancement in terms of average wind power. In terms of maximum wind power, according to RCP4.5 the highest enhancement occur in the Baltic Sea (P5 corresponding to the wind farm EnBW Baltic 1, with maximum wind power values of almost $25000 \mathrm{~W} / \mathrm{m}^{2}$ ) and in the Mediterranean Sea (P6, located in the coastal environment south of France, with maximum wind power values of almost $20000 \mathrm{~W} / \mathrm{m}^{2}$ ). On the other hand, RCP8.5 indicates strongest enhancements in the western side of the Black Sea, where we can expect maximum wind power values of almost $35000 \mathrm{~W} / \mathrm{m}^{2}$. According to the same scenario (RCP8.5) in the Baltic Sea the enhancement of the maximum wind power is expected to be not so accentuated as in the case of RCP4.5.

The work is still on going and the analysis will be extended in both space, covering more coastal locations that present interest for the wind energy extraction, and time extending the period until the end of the $21^{\text {st }}$ century.

\section{Acknowledgements}

The work of the first author was supported by the project "Excellence, performance and competitiveness in the Research, Development and Innovation activities at "Dunarea de Jos" University of Galati", acronym "EXPERT", financed by the Romanian Ministry of Research and Innovation in the framework of Programme 1-Development of the national research and development system, Sub-programme 1.2Institutional Performance - Projects for financing excellence in Research, Development and Innovation, Contract no. 14PFE/17.10.2018. The work of the third author was supported by the project ANTREPRENORDOC, in the framework of Human Resources Development Operational Programme 20142020, financed from the European Social Fund under the contract number 36355/23.05.2019 HRD OP /380/6/13 - SMIS Code: 123847.

\section{References}

1. Makris, C., Galiatsatou, P., Tolika, K., et al., 2016, Climate change effects on themarine characteristics of the Aegean and Ionian Seas, Ocean Dynamics, 66, 1603-1635,

2. Onea, F., Rusu, E., 2018, "Sustainability of the Reanalysis Databases in Predicting the Wind and Wave Power along the European Coasts", Sustainability 2018, 10(1), 193,

3. Onea, F, Ciortan, S; Rusu, E., 2017, Assessment of the potential for developing combined wind-wave projects in the European nearshore, Energy \& Environment Volume: 28, Issue: 5-6 Pages: 580-597

4. Onea, F; Rusu, L. 2019, Evaluation of some State-Of-The-Art Wind technologies in the Nearshore of the Black Sea. Energies 2018, 11, 2452.

5. Onea, F, Rusu, E., 2016, Efficiency assessments for some state of the art wind turbines in the coastal environments of the Black and the Caspian seas, Energy Exploration \& Exploitation Volume: 34 Issue: 2 Pages: $217-$ 234.

6. Colmenar-Santos A, Perera-Perez $\mathbf{J}$ and BorgeDiez D (2016) Offshore wind energy: A review of the current status, challenges and future development in Spain. Renewable and Sustainable Energy Reviews 64: 1-18

7. Rusu, E.; Onea, F., 2017 Joint Evaluation of the Wave and Offshore Wind Energy Resources in the Developing Countries, Source: 
Energies Volume: 10 Issue: 11 Pages: 20 Published: 2017

8. Raileanu, A. B.; Onea, F.; Rusu, E.; 215, Evaluation of the offshore wind resources in the European seas based on satellite measurements, Energy and Clean Technologies Pages: 227-234.

9. Onea, F, Rusu, E., 2014, Wind energy assessments along the Black Sea basin, Meteorological Applications, Volume: 21 Issue: 2 Pages: 316-329.

10. Onea, F., Raileanu, A., Rusu, E., 2015, Evaluation of the Wind Energy Potential in the Coastal Environment of Two Enclosed Seas, Advances in Meteorology.

11. European Centre for Medium-Range Weather Forecasts (ECMWF), IFS Documentation Cy31r1, Operational implementation. Part VII: ECMWF wave mode. European Centre for Medium-Range Weather Forecasts, Shinfield Park, Reading, England (2006).

12. P. Samuelsson, C.G. Jones, U. Willen, A. Ulerstig, The Rossby Centre Regional Climate model RCA3: model description and performance, Special issue on Regional climate studies using the SMHI-Rossby Centre models, Tellus 63A (No. 1) (Jan. 2011) 4-23.

13. M.A. Giorgetta, J. Jungclaus, C.H. Reick, S. Legutke, et al., Climate and carbon cycle changes from 1850 to 2100 in MPI-ESM simulations for the Coupled Model Intercomparison Project phase 5, J. Adv. Model. Earth Syst. 5 (2013) 572-597.

14. R.H. Moss, J.A. Edmonds, K.A. Hibbard, M.R. Manning, S.K. Rose, et al., The next generation of scenarios for climate change research and assessment, Nature 463 (No. 7282) (2010) 747-756.
15. Stull R (2015) Practical Meteorology: an Algebra Based Survey of Atmospheric Science. University of British Columbia, Vancouver, Canada.

16. Rusu, E., 2019, Wind energy assessments in the Baltic Sea, past and future projections, $4^{\text {th }}$ Conference on Sustainable Development of Energy, Water and Environment Systems SDEWES Conference, 1 - 6 October, 2019 Dubrovnik, Croatia SDEWES2019.390

17. Rusu, E., Rusu, L., 2019, Evaluation of the wind power potential in the European nearshore of the Mediterranean Sea, 4th International Conference on Advances on Clean Energy Research (ICACER 2019), Coimbra, Portugal, April 5-7, 2019,

18. Ganea, D., Amorțilă, V., Mereuță, E., Rusu, E., 2017, A Joint Evaluation of the Wind and Wave Energy Resources Close to the Greek Islands, Sustainability Journal, Special Issue Wind Energy, Load and Price Forecasting towards Sustainability, 2017, 9(6),

19. Rusu, E., 2019, A 30-year projection of the future wind energy resources in the coastal environment of the Black Sea, Renewable Energy, Volume 139, pp. 228-234

20. Diaconita, A, Onea, F, Rusu, E., 2019, An Evaluation of the Wind Energy in the North Sea Coast, Mechanical Testing and Diagnosis ISSN 2247-9635, 2019 (IX), Volume 1, pp. 1722. 